The Open Civil Engineering Journal
CrossMark
Content list available at: www.benthamopen.com/TOCIEJ/
DOI: $10.2174 / 1874149501711010033$

RESEARCH ARTICLE

\title{
Energy Absorption and Crush Behavior of the Layered Aluminum Honeycomb
}

\author{
Weiming Luo*, Shaoqing Shi, Zipeng Chen and Jianhu Sun \\ Department of Civil Engineering, Logistical Engineering University, Chongqing 401331, China
}

\begin{abstract}
To investigate the energy absorption characteristics and crush behavior of layered aluminum honeycomb, the experiments of layered aluminum honeycomb structure under quasi-static load had been carried out, mainly includes single, double, triple, four layer combinations. The results showed that: the peak force and the mean plateau force of single-layer aluminum honeycomb structure are proportional to the surface density, however they decline slightly with increase of the height; unequal height double layered aluminum honeycomb structure has more advantage in cushion performance; with the increase of layers, the MP ratio will decrease; the combination of placing soft layer between hard layers is better than the others.
\end{abstract}

Keywords: Layered Aluminum Honeycomb, Energy Absorption, Crush Behavior, Buffer, Plateau.

\section{INTRODUCTION}

Due to the energy-absorption capability, sound and heat insulation, aluminum honeycomb is widely used in packaging, aerospace, shipbuilding, construction, energy and other fields. Khan et al. had found that the out-of-plane was the strongest direction which absorbed significant amount of energy during deformation [1]. Therefore, it is used in high-speed rail train, aircraft landing gear, instruments packaging, etc. The key characteristic of buffer is to lower force of the protected object that should be less than its failure stress and absorb considerable energy.

Wilbert et al. [2] tested the honeycomb compression experiment and simulated the process of buckling and folding, they found that reasons the stress vibrated in the plateau stage. Wang Chuang et al. [3] analyzed an Y-shaped crosssection structure of honeycomb cell, the formula for calculating relative density of honeycomb with regular hexagon cell shape was derived. Xu Shanqing et al. [4] found that the relative density of aluminum honeycomb and strain rate of loading effected on the deformation behavior, and numerical simulation results [5] showed that $t / 1$ ratio (wall thickness to edge length ratio) and strain rate had great influence on the deformation pattern and plateau stress. Sun Deqiang et al. [6] demonstrated the all configuration parameters are constant, mean out-of-plane dynamic plateau stresses are related to impact velocities and edge length ratios. Niknejad et al. [7] proposed a theoretical model for analysis of quasi-static compressing deformation of aluminum honeycomb and found that the filling of polyurethane foam, foil thickness, side length of hexagon had a greater influence on the compressive strength of honeycomb. Lu Wenhao et al. [8] used theoretical analysis and FE simulation to demonstrate the relationship between the thickness of the cellar wall, the ratio of the $\mathrm{t} / \mathrm{l}$ and the in-plane elastic property under dynamic impact load. Wu Enboa et al. [9] studied mechanical behavior and energy absorption ability of different types of honeycombs under quasi-static compression and dynamic pendulum impact. By diminishing size or reducing height of honeycomb, or using high strength material can improve the ability of energy absorption per unit volume. Yamashita et al. [10] utilized drop hammer and numerical simulation for researching on compression behavior of honeycomb, and results showed that the compression strength increase was caused by compressed air in honeycomb. Tan Sibo et al. [11] experimentally investigated two kinds of aluminum honeycomb with same geometric parameters and different material. Obvious dynamic enhancement phenomenon was

\footnotetext{
* Address correspondence to this author at the Department of Civil Engineering, Logistical Engineering University, Chongqing 401331, China; Tel: +8618223143182; E-mail: lwmofficial@163.com
} 
found. Transverse inertia theory can explain the dynamic behavior and high strain hardening of aluminum honeycomb material. Ashab et al. [12] found that the strain rate and nominal density influenced on the tearing energy of honeycomb.

As mentioned above, most research of the aluminum honeycomb is limited to in-plane and out-of-plane study of the quasi-static or dynamic compression of aluminum honeycomb. Only relevant studies of layered aluminum honeycomb had been carried out by Lin Yuliang et al. [13], they designed and tested a cylindrical cushioning structure with two types of aluminum honeycomb. Their experimental results showed that combined honeycomb buffer consisted of multilayered honeycomb samples should be given priority in the optimization design of aluminum honeycomb buffer. Cao et al. also tested the dynamic performance of the combination of aluminum honeycomb [14]. Results showed that shock absorbing characteristic of combined aluminum honeycomb buffer is better, and the suitable combination can smooth the stress and lower the energy applied to the testing platform. However, in their work, only a limited number of combinations are tested. Therefore, more experiments will be carried out in this paper for further investigation on energy absorption and crush behavior of the layered aluminum honeycomb.

\section{EXPERIMENT}

SANS CMT5105 testing machine is used for quasi-static uniaxial compression. The displacement control is set as $2 \mathrm{~mm} / \mathrm{min}$. Besides, the force and displacement data are collected by the computer. In order to diminish the influences from the aluminum honeycomb hexagonal size, material and many other variables, the thickness " $t$ " of foil was controlled in $0.04 \mathrm{~mm}$. The specification is shown in Fig. (1), only two variables were left: hexagonal side length " $l$ " and the height " $h$ " of honeycomb. Besides, considering about reducing the quantities of permutation and combination, the specimens' types are divided into A, B, B1 and B2. The dimension of all specimens are controlled within $100 \mathrm{~mm} \times 100 \mathrm{~mm}( \pm 0.5 \mathrm{~mm})$, and the specimens size are shown in Table $\mathbf{1}$.

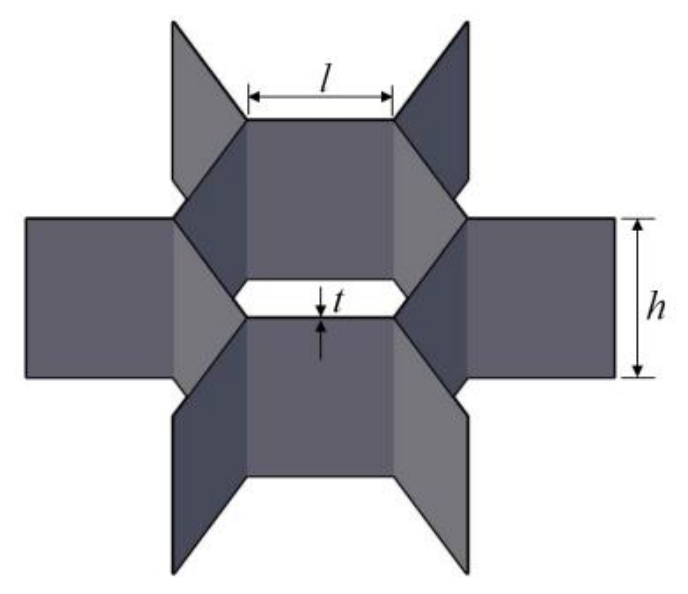

Fig. (1). Specification.

\section{RESULTS AND DISCUSSION}

\subsection{Single Layer Aluminum Honeycomb}

Four types of specimens are tested in the machine three or more times to select valid curves. The mean values of test data from single layer aluminum honeycomb are compared in Table 2. In order to compare the experimental data, the force-displacement curve and the integral area surrounded by the mean value curve and the $\mathrm{X}$ axis, all these factors are respectively characterized in Fig. (2). It can be found that the curves of each test have little difference with each other, which means that the process of crushing is relatively stable; the curve can be separated into four stages: ascent stage of elasticity, decline stage of yield, plateau stage of plasticity, ascent stage of densification. Crushed single layer aluminum honeycombs are shown in Fig. (3).

The research used the integral value to represent the energy absorption properties and made the energy absorption per millimeter represent the absorbing energy levels. At the same time, we set a MP ratio, so as to compare the ratio of peak force and the mean plateau force. This value shows that the greater this value is, the more adverse to the energy absorption, and vice versa. 


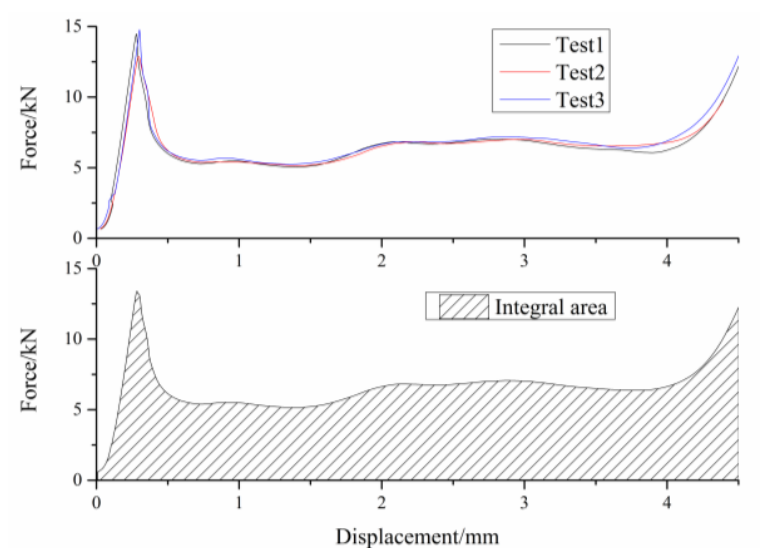

(a) $\mathrm{A}$

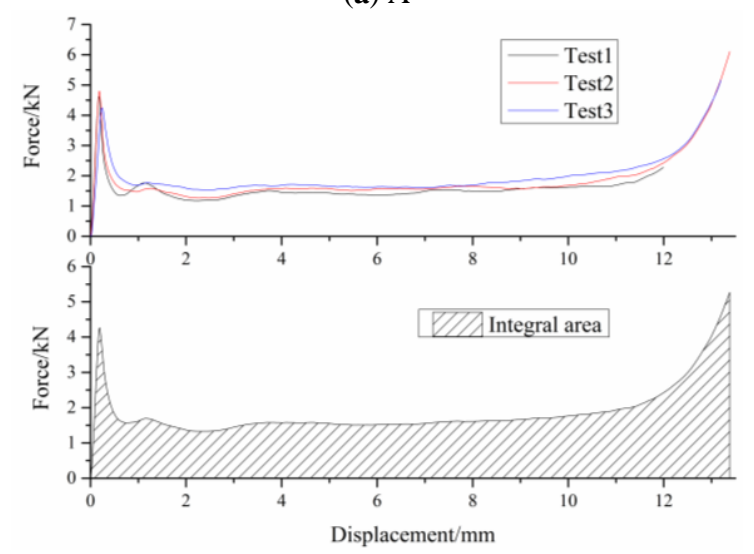

(c) B1

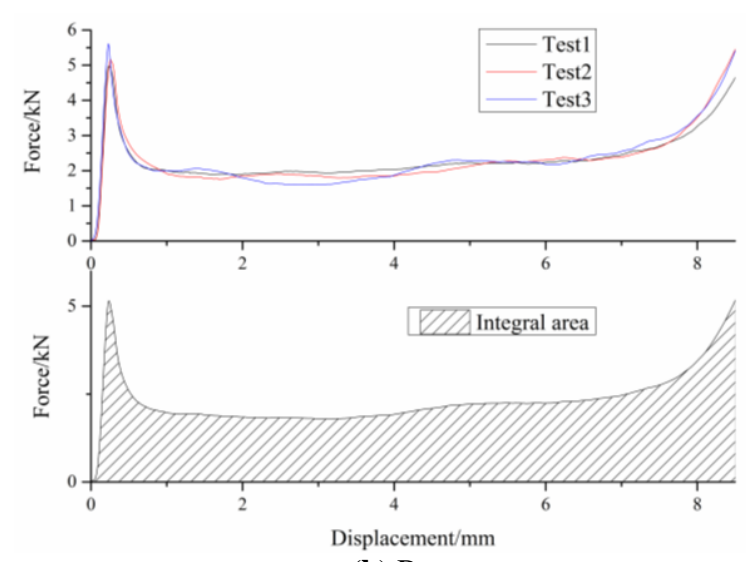

(b) $\mathrm{B}$

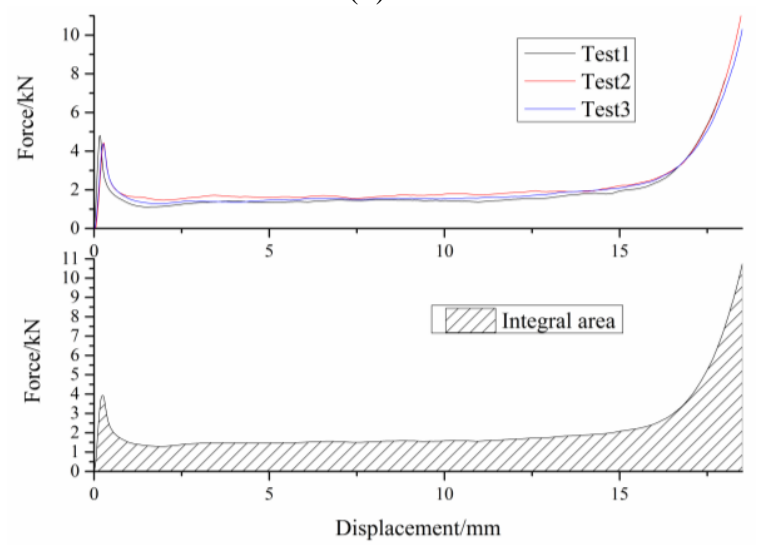

(d) B2

Fig. (2). Mechanical response of single layer aluminum honeycombs.

It can be inferred that the peak force is almost 2 3 times than the mean plateau force. Since the A specimen unit size is small with high surface density. The peak force and the mean plateau force were higher than that of $\mathrm{B} \sim \mathrm{B} 2$ with bigger unit size. The absorbing energy level of $\mathrm{A}$ is almost 3 times of the latter's. Compared with B B2, with the increase of height, peak force and mean plateau force will decline slightly. This is due to the height of aluminum foil lining increases can easily lead to buckling.

Table 1. Specimens size.

\begin{tabular}{|c|c|c|c|c|}
\hline Specimens & A & B & B1 & B2 \\
\hline Layout & $22 * 17$ & $9 * 8$ & $9 * 8$ & $9 * 8$ \\
\hline$l / \mathrm{mm}$ & 3 & 7 & 7 & 7 \\
\hline$t / \mathrm{mm}$ & 0.04 & 0.04 & 0.04 & 0.04 \\
\hline$h / \mathrm{mm}$ & 5 & 10 & 15 & 20 \\
\hline
\end{tabular}

Table 2. Mean values of test data from single layer aluminum honeycombs.

\begin{tabular}{|c|c|c|c|c|c|c|}
\hline Specimens & Peak force/kN & Mean plateau force $/ \mathrm{kN}$ & MP ratio & Integral displacement/mm & Integral value/J & $\begin{array}{l}\text { Absorbing energy } \\
\text { levels } / \mathbf{J} \cdot \mathbf{m m}-1\end{array}$ \\
\hline A & 13.3844 & 6.3684 & 2.1017 & 4.5 & 29.4761 & 6.5502 \\
\hline B & 5.1575 & 2.0717 & 2.4895 & 8.5 & 19.6096 & 2.3070 \\
\hline B1 & 4.2675 & 1.5878 & 2.6876 & 13.5 & 25.1105 & 1.8600 \\
\hline B2 & 3.9026 & 1.5469 & 2.5229 & 18.5 & 34.1574 & 1.8463 \\
\hline
\end{tabular}




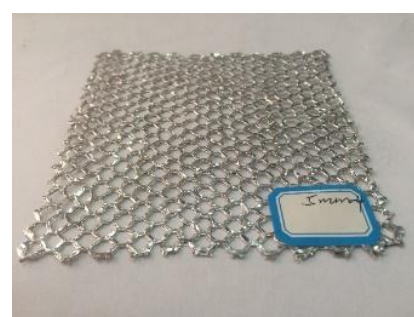

(a) $\mathrm{A}$

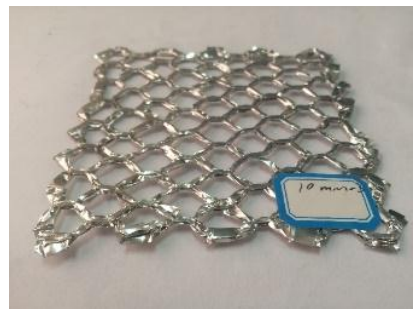

(b) B

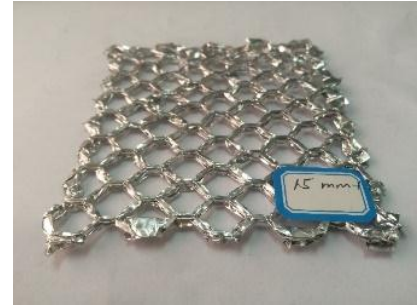

(c) B1

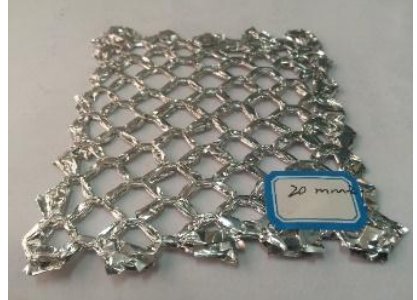

(d) B2

Fig. (3). Crushed single layer aluminum honeycombs.

\subsection{Double Layered Aluminum Honeycomb}

The quasi-static uniaxial compression of the double layered aluminum honeycomb included $\mathrm{A}+\mathrm{A}, \mathrm{A}+\mathrm{B}$ and $\mathrm{B}+\mathrm{B}$ three combinations. Since the B, B1 and B2 honeycomb unit size only differ from the height, B sample was selected to represent $\mathrm{B} 1$ and $\mathrm{B} 2$. The experimental results show that: the curve characteristics of $\mathrm{A}+\mathrm{A}$ and $\mathrm{B}+\mathrm{B}$ with two equal layer, is that the curve has mutual inserting period and combined compressing period. However, the curve characteristics of $\mathrm{A}+\mathrm{B}$ with unequal height layers had mutual inserting period at first (the A layer with $5 \mathrm{~mm}$ height started to insert into the B layer with $10 \mathrm{~mm}$ height). Moreover, the B layer with 10mm height, which had A layer inside, was compressed until 5mm height. Finally, the A layer and B layer were compressed and densified together as shown in the Fig. (4). The phenomenon can also be found in the form of curve as Fig. (5). Since the honeycomb structure with equal height layers would enter into the yield stage after mutual inserting, it was equivalent to make the peak force into superposition. On the other hand, the honeycomb structure with unequal height layers would yield in two stages, the peak force would be separated into two parts. Therefore, the honeycomb with unequal height layers has better buffer performance which can be inferred from the MP ratio in Table 3. Crushed double layered aluminum honeycombs are shown in Fig. (6).

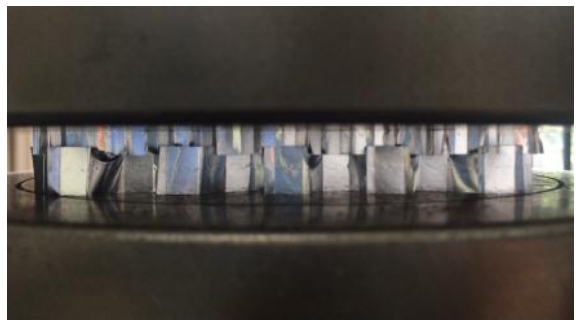

(a) Inserting

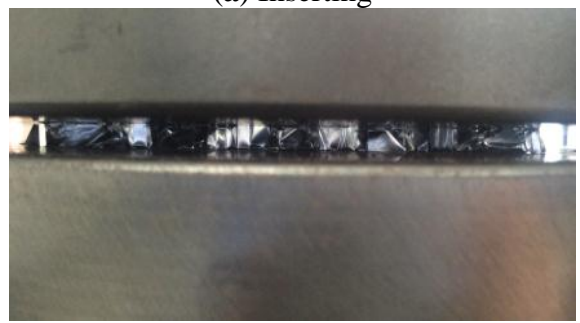

(c) Compress A and B

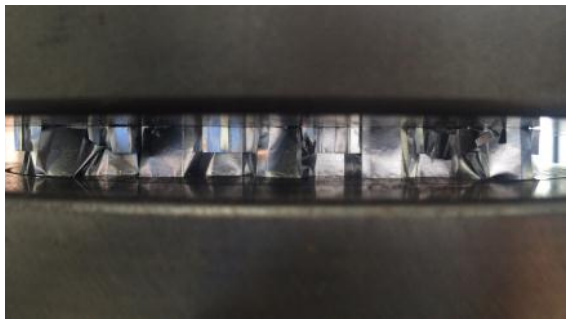

(b) Compress B

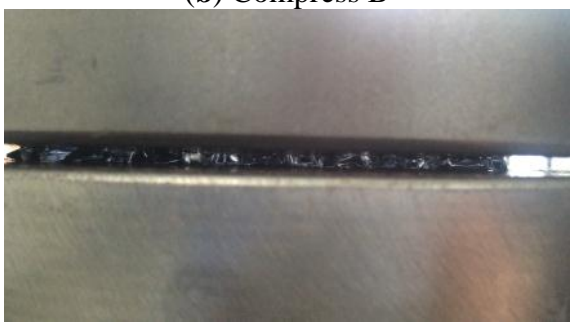

(d) Densification

Fig. (4). The crushing progress of $A+B$ double layered aluminum honeycomb.

Table 3. Mean values of test data from double layered aluminum honeycombs.

\begin{tabular}{|c|c|c|c|c|c|c|c|}
\hline Specimens & $\begin{array}{c}\text { Mean inserting } \\
\text { force/kN }\end{array}$ & Peak force/kN & $\begin{array}{c}\text { Combined mean } \\
\text { plateau force/kN }\end{array}$ & MP ratio & $\begin{array}{c}\text { Integral } \\
\text { displacement/mm }\end{array}$ & $\begin{array}{c}\text { Integral } \\
\text { value/J }\end{array}$ & $\begin{array}{c}\text { Absorbing energy } \\
\text { levels/J· } \mathbf{m m}^{-1}\end{array}$ \\
\hline $\mathrm{A}+\mathrm{A}$ & 2.6331 & 14.6397 & 11.6128 & 1.2606 & 9.5 & 65.3604 & 6.8800 \\
\hline $\mathrm{A}+\mathrm{B}$ & 1.1678 & 8.2447 & 7.5642 & 1.0899 & 13.5 & 46.2927 & 3.4291 \\
\hline $\mathrm{B}+\mathrm{B}$ & 0.7692 & 5.4195 & 3.3583 & 1.6137 & 18.5 & 43.8296 & 2.3692 \\
\hline
\end{tabular}




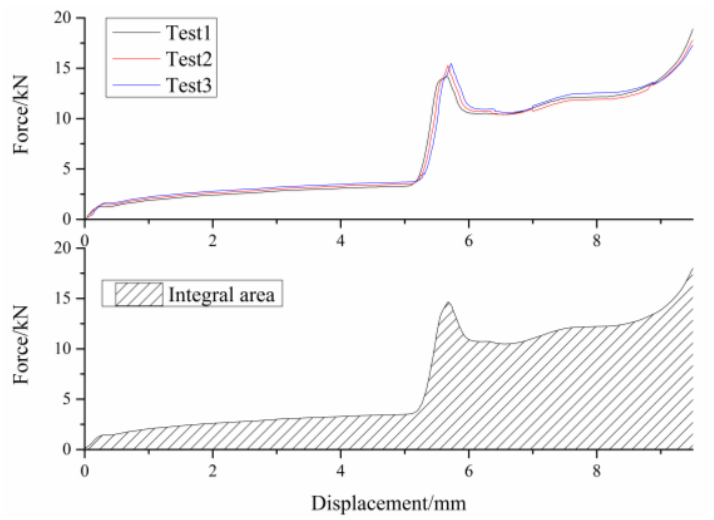

(a) $\mathrm{A}+\mathrm{A}$

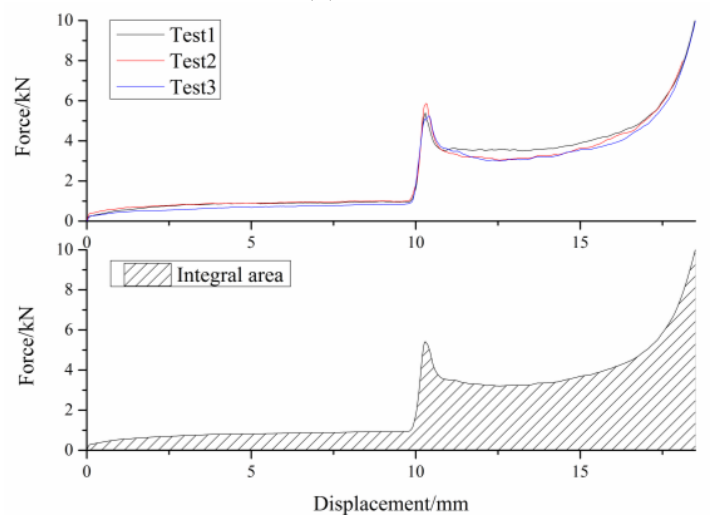

(c) $\mathrm{B}+\mathrm{B}$

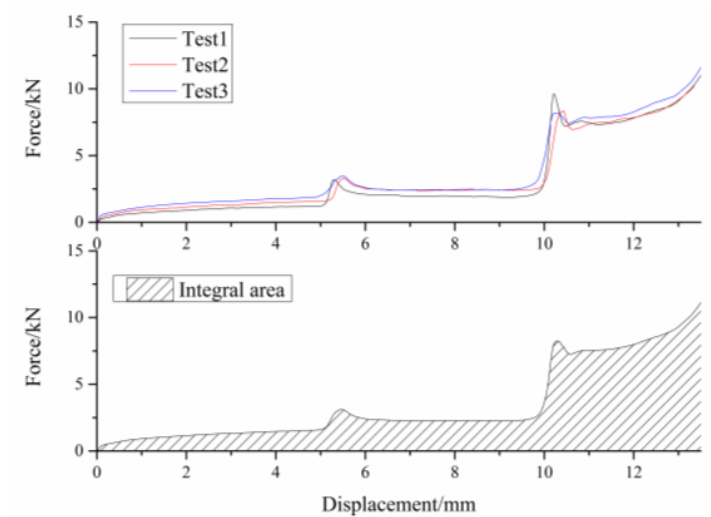

(b) $\mathrm{A}+\mathrm{B}$

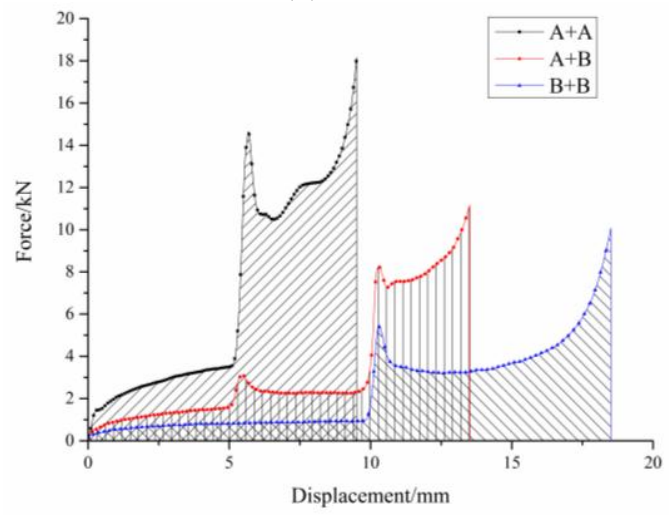

(d) Contrast

Fig. (5). Mechanical response of double layered aluminum honeycombs.

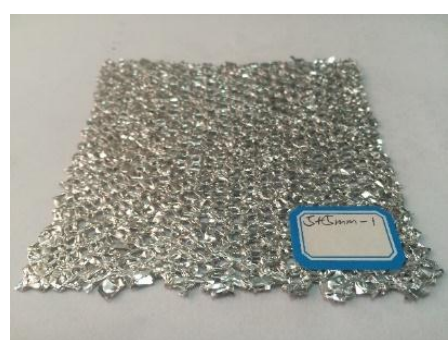

(a) $\mathrm{A}+\mathrm{A}$

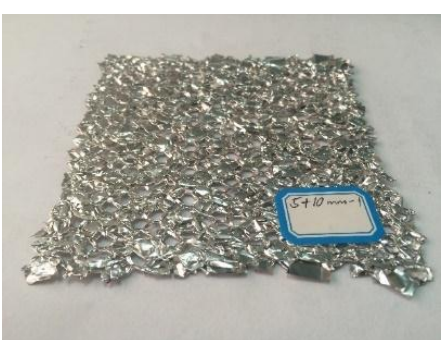

(b) $\mathrm{A}+\mathrm{B}$

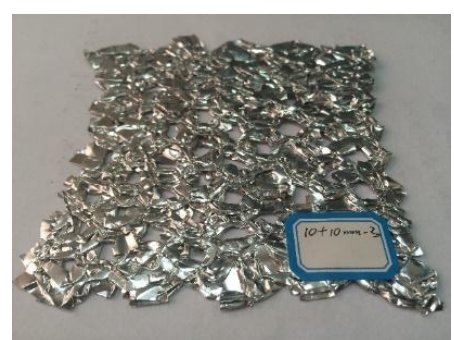

(c) $\mathrm{B}+\mathrm{B}$

Fig. (6). Crushed double layered aluminum honeycombs.

\subsection{Triple Layered Aluminum Honeycomb}

Since the B honeycomb has smaller stiffness than A, the former is softer. In order to investigate this kind of soft layer has what influence to the structure, the structure with three $B$ layers was set. Thus, there are 4 combining forms: $\mathrm{A}+\mathrm{A}+\mathrm{A}, \mathrm{A}+\mathrm{B}+\mathrm{A}, \mathrm{A}+\mathrm{A}+\mathrm{B}$ and $\mathrm{B}+\mathrm{B}+\mathrm{B}$. It can be found that: in the early stage of the compression (displacement between $0 \sim 15 \mathrm{~mm}$ ), the structure was in the mutual inserting period, which took $81.08 \%$ of the compression process. Besides, the combined crushing stage was moved backward, and the plateau stage was closer to the densification stage, which is the reason why the curves of honeycombs with three layers is more smooth than the curves of the honeycombs with two layers.

It can be seen from the Fig. (7) and the Table 4, the absorbing energy level of $\mathrm{A}+\mathrm{A}+\mathrm{A}$ combination is the highest among the triple layered aluminum honeycombs. However, the energy absorption performance of this combination is not ideal, since the peak force is too high to protect the object that the impact stress should not be greater than its failure stress. 


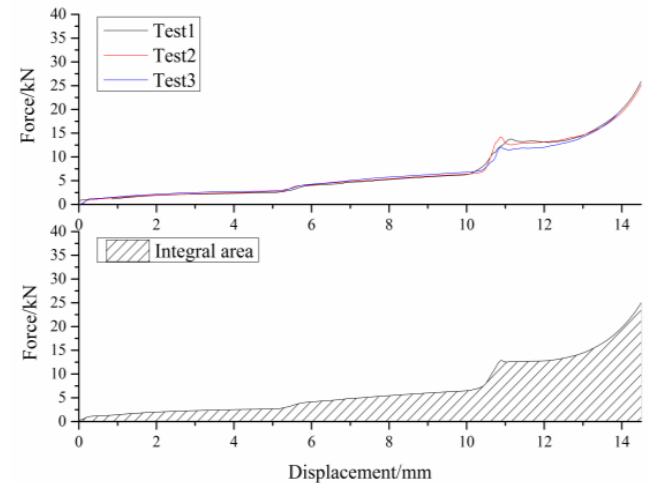

(a) $\mathrm{A}+\mathrm{A}+\mathrm{A}$

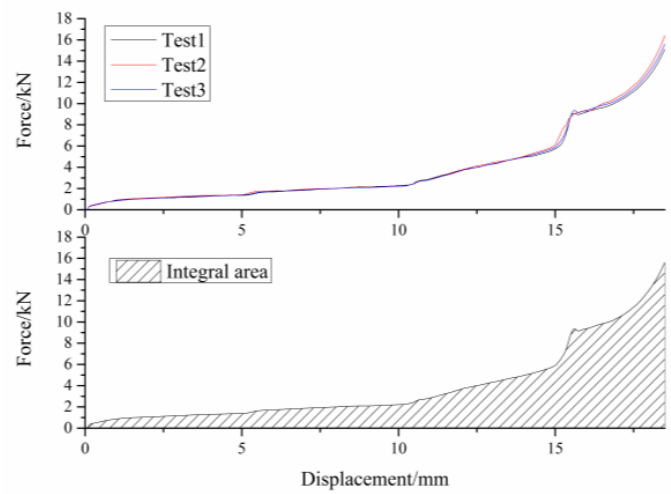

(c) $\mathrm{A}+\mathrm{A}+\mathrm{B}$

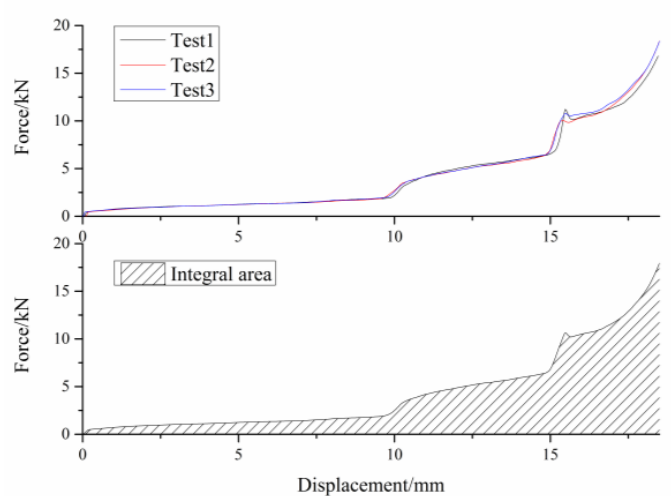

(b) $\mathrm{A}+\mathrm{B}+\mathrm{A}$

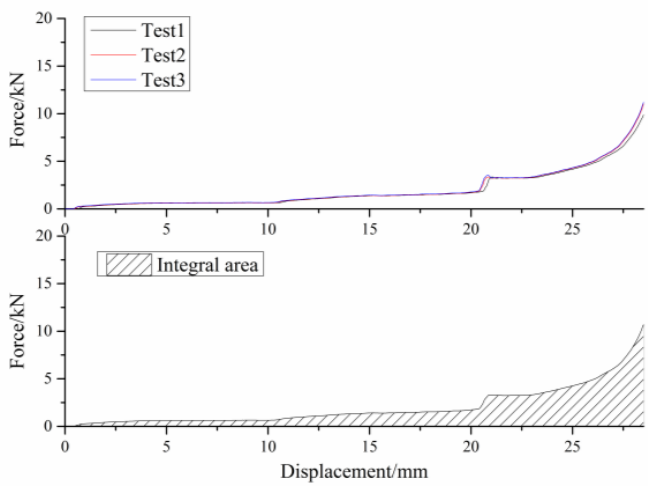

(d) $\mathrm{B}+\mathrm{B}+\mathrm{B}$

Fig. (7). Mechanical response of triple layered aluminum honeycombs.

By comparing the $\mathrm{A}+\mathrm{B}+\mathrm{A}$ combination and the $\mathrm{A}+\mathrm{A}+\mathrm{B}$ combination, the former has better ability in energy absorption than the latter's, which is relevant with the crush behavior. Even though there is no significant difference between the inserting force, peak force, combined plateau force and the MP ratio. For the A+B $+\mathrm{A}$ combination, since the two A layers could insert the B layer in the same time (displacement between $0 \sim 10 \mathrm{~mm}$ ), then the two A layers would contact and insert into each other when the compression displacement was $10 \mathrm{~mm}$. When those two A layers were inserting into each other, the B layer was also crushed with them. Since the mean force was higher, the ability of absorbing energy is also better. However, for the $\mathrm{A}+\mathrm{A}+\mathrm{B}$ combination, the $\mathrm{A}$ layer in the middle would insert into the $\mathrm{B}$ layer at first, then the top A layer inserted into them. During the compression process, the B layer already had some plastic deformations in the inserting period. Thus, the force was higher than that of $\mathrm{A}+\mathrm{B}+\mathrm{A}$ combination in this period, and that's the reason why the B layer in the late period (displacement between $10 \sim 18.5 \mathrm{~mm}$ ) did not show better energy absorption performance. So, in this period the curve of the $\mathrm{A}+\mathrm{A}+\mathrm{B}$ is lower than the $\mathrm{A}+\mathrm{B}+\mathrm{A}$ combination. Crushed triple layered aluminum honeycombs are shown in Fig. (8). The contrast of the force-displacement curves are shown in Fig. (9).

By comparing the $\mathrm{B}+\mathrm{B}$ and $\mathrm{B} 2$ in the Table $\mathbf{5}$, it shows that the $\mathrm{B}+\mathrm{B}$ combination has lower MP ratio and more energy absorption than the $\mathrm{B} 2$, but it has higher peak force. By comparing the $\mathrm{B}$, the $\mathrm{B}+\mathrm{B}$ and the $\mathrm{B}+\mathrm{B}+\mathrm{B}$ combination, it shows that with the increase of layers, the MP ratio will decrease.

Table 4. Mean values of test data from triple layered aluminum honeycombs.

\begin{tabular}{|c|c|c|c|c|c|c|c|}
\hline Specimens & $\begin{array}{c}\text { Mean inserting } \\
\text { force/kN }\end{array}$ & Peak force/kN & $\begin{array}{c}\text { Combined plateau } \\
\text { force/kN }\end{array}$ & MP ratio & $\begin{array}{c}\text { Integral } \\
\text { displacement/mm }\end{array}$ & $\begin{array}{c}\text { Integral } \\
\text { value/J }\end{array}$ & $\begin{array}{c}\text { Absorbing energy } \\
\text { levels/J·mm-1 }\end{array}$ \\
\hline $\mathrm{A}+\mathrm{A}+\mathrm{A}$ & 3.4932 & 12.8682 & 12.6739 & 1.0153 & 14.5 & 97.9561 & 6.7556 \\
\hline $\mathrm{A}+\mathrm{B}+\mathrm{A}$ & 1.2509 & 10.6354 & 10.5231 & 1.0107 & 18.5 & 79.1472 & 7.2782 \\
\hline $\mathrm{A}+\mathrm{A}+\mathrm{B}$ & 1.4573 & 9.3415 & 9.2987 & 1.0046 & 18.5 & 70.7828 & \\
\hline $\mathrm{B}+\mathrm{B}+\mathrm{B}$ & 0.6534 & 3.2721 & 3.2614 & 1.0033 & 28.5 & 61.3045 & \\
\hline
\end{tabular}




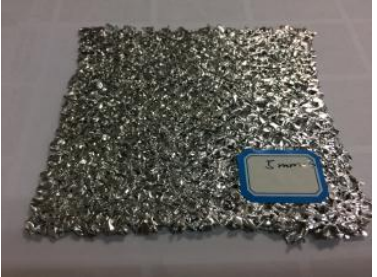

(a) $\mathrm{A}+\mathrm{A}+\mathrm{A}$

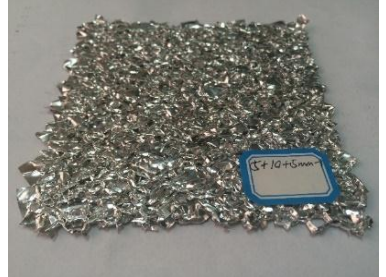

(b) $\mathrm{A}+\mathrm{B}+\mathrm{A}$

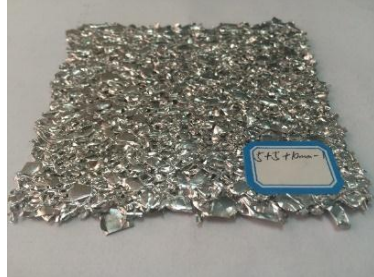

(c) $\mathrm{A}+\mathrm{A}+\mathrm{B}$

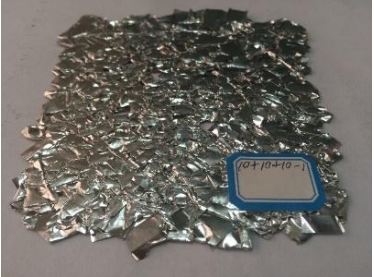

(d) $\mathrm{B}+\mathrm{B}+\mathrm{B}$

Fig. (8). Crushed triple layered aluminum honeycombs.

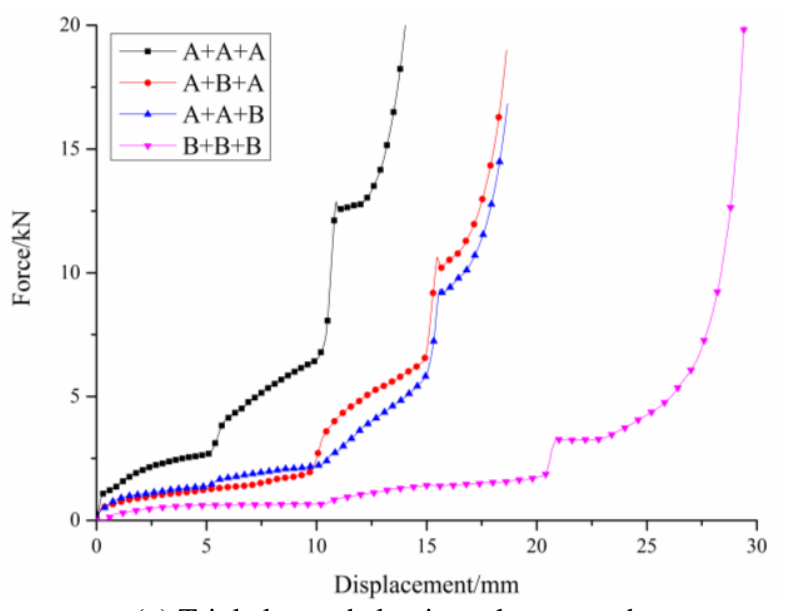

(a) Triple layered aluminum honeycombs

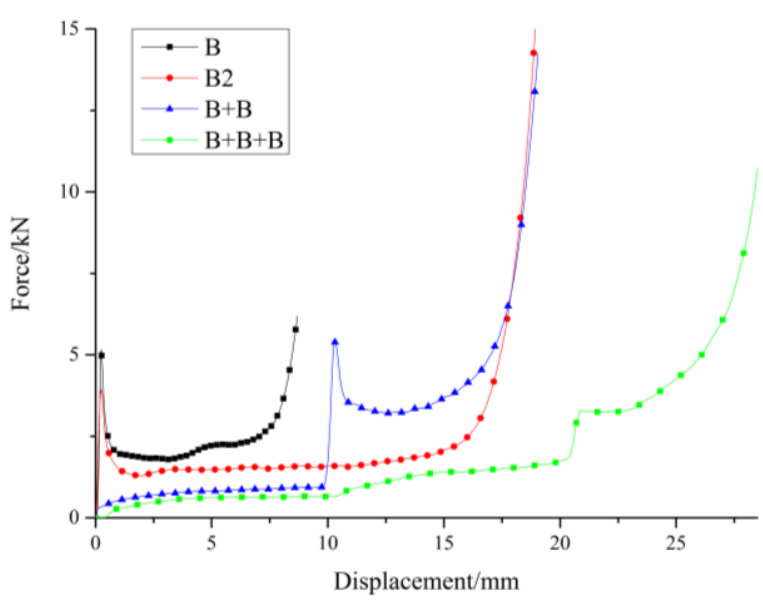

(b) B type layered aluminum honeycombs

Fig. (9). Contrast of the force-displacement curves.

Table 5. Mean values of test data from B type layered aluminum honeycombs.

\begin{tabular}{|c|c|c|c|c|c|c|c|}
\hline Specimens & $\begin{array}{c}\text { Mean inserting } \\
\text { force/kN }\end{array}$ & Peak force/kN & $\begin{array}{c}\text { Combined plateau } \\
\text { force/kN }\end{array}$ & MP ratio & $\begin{array}{c}\text { Integral } \\
\text { displacement/mm }\end{array}$ & Integral value/J & $\begin{array}{c}\text { Absorbing energy } \\
\text { levels/J·mm-1 }\end{array}$ \\
\hline B & - & 5.1575 & 2.0717 & 2.4895 & 8.5 & 19.6096 & 2.3070 \\
\hline B2 & - & 3.9026 & 1.5469 & 2.5229 & 18.5 & 34.1574 & 1.8463 \\
\hline B+B & 0.7692 & 5.4195 & 3.3583 & 1.6137 & 18.5 & 43.8296 & 2.3692 \\
\hline B+B+B & 0.6534 & 3.2721 & 3.2614 & 1.0033 & 28.5 & 61.3045 & 2.1510 \\
\hline
\end{tabular}

\subsection{Four Layered Aluminum Honeycomb}

In order to figure out the influences of the layer number and the distribution of layers to the layered aluminum honeycomb structure, 4 combinations were set for four layered aluminum honeycomb: $A+A+B+B, A+B+A+B$, $\mathrm{A}+\mathrm{B}+\mathrm{B}+\mathrm{A}$ and $\mathrm{B}+\mathrm{A}+\mathrm{A}+\mathrm{B}$. The mechanical response of four layered aluminum honeycombs. are shown in Fig. (10). Results show that: the early period of the compression (displacement between $0 \sim 25 \mathrm{~mm}$ ) was mutual inserting period, which was about $87.72 \%$ of the whole compression process, and the combined crushing stage and the densification stage only accounted for $12.28 \%$. Besides, there was no apparent boundary between the plateau stage and the densification stage. Thus, the force-displacement curve of the honeycombs with four layers became more smooth. Moreover, the distribution made little difference between the structures' mechanical properties. It showed that the mean value had little differences between each other in Table 6 and curves are almost the same which is shown in the Fig. (11). However, the energy absorption of $A+B+B+A$ is the best among 4 combinations. In the section 3.3 , results also show that the $\mathrm{A}+\mathrm{B}+\mathrm{A}$ has better energy absorption performance. It can be inferred that the combination of placing soft layer between hard layers is better than the others. Crushed four layered aluminum honeycombs are shown in Fig. (12).

Basing on the crush behavior, it can be inferred that: when the honeycomb structure has more than 3 layers, since the inserting stage in the early process becomes longer, the yield stage, the plastic plateau stage and the densification stage will intertwine, showing a smoother force-displacement curve. Nevertheless, because of this characteristic, the plateau stage which is the main energy absorption stage can hardly play a part. 


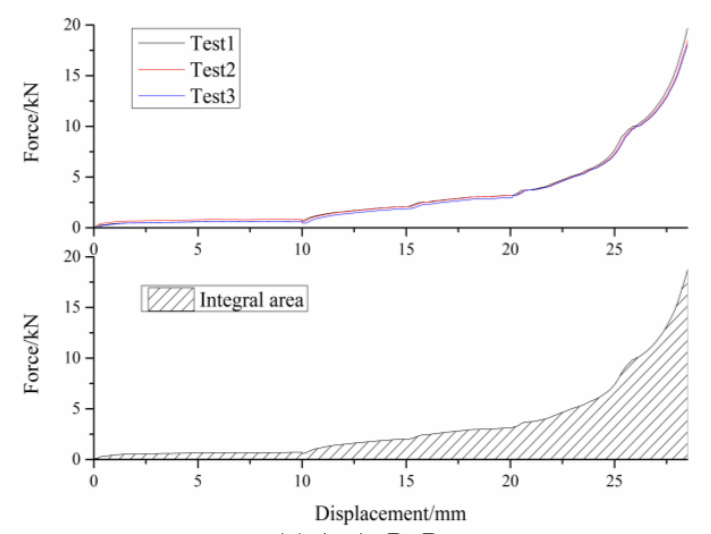

(a) $\mathrm{A}+\mathrm{A}+\mathrm{B}+\mathrm{B}$

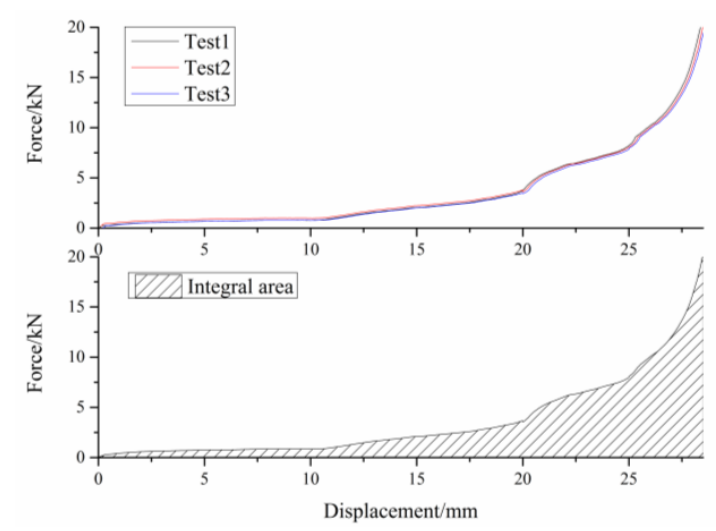

(c) $\mathrm{A}+\mathrm{B}+\mathrm{B}+\mathrm{A}$

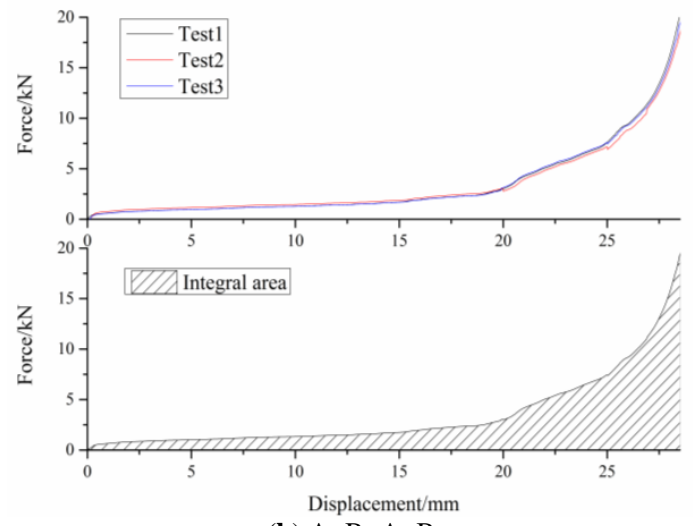

(b) $\mathrm{A}+\mathrm{B}+\mathrm{A}+\mathrm{B}$

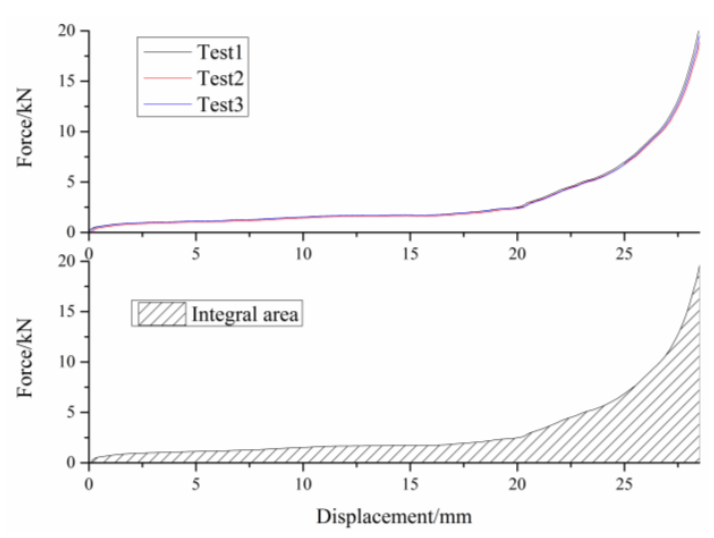

(d) $\mathrm{B}+\mathrm{A}+\mathrm{A}+\mathrm{B}$

Fig. (10). Mechanical response of four layered aluminum honeycombs.

Table 6. Mean values of test data from four layered aluminum honeycombs.

\begin{tabular}{|c|c|c|c|}
\hline Specimens & Integral displacement/mm & Integral value/J & Absorbing energy levels/J·mm-1 \\
\hline $\mathrm{A}+\mathrm{A}+\mathrm{B}+\mathrm{B}$ & 28.5 & 92.17037 & 3.2340 \\
\hline $\mathrm{A}+\mathrm{B}+\mathrm{A}+\mathrm{B}$ & 28.5 & 95.54899 & 3.3526 \\
\hline $\mathrm{A}+\mathrm{B}+\mathrm{B}+\mathrm{A}$ & 28.5 & 101.01004 & 3.5442 \\
\hline $\mathrm{B}+\mathrm{A}+\mathrm{A}+\mathrm{B}$ & 28.5 & 90.16385 & 3.1636 \\
\hline
\end{tabular}

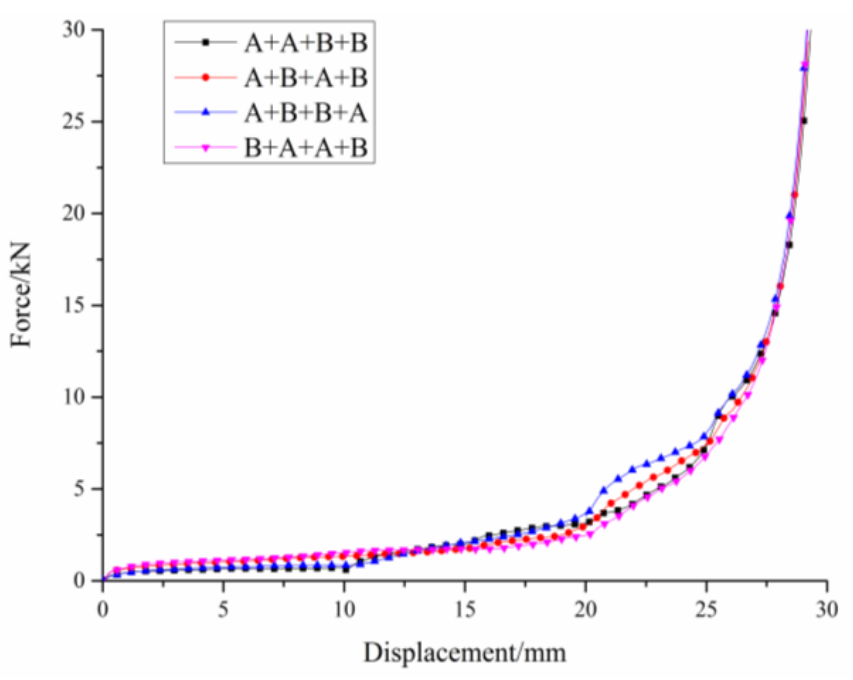

Fig. (11). Contrast of four layered aluminum honeycombs. 


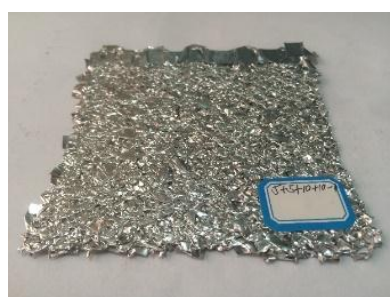

(a) $\mathrm{A}+\mathrm{A}+\mathrm{B}+\mathrm{B}$

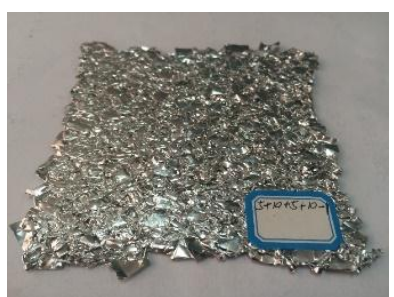

(b) $\mathrm{A}+\mathrm{B}+\mathrm{A}+\mathrm{B}$

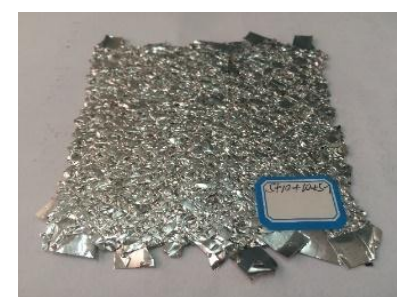

(c) $\mathrm{A}+\mathrm{B}+\mathrm{B}+\mathrm{A}$

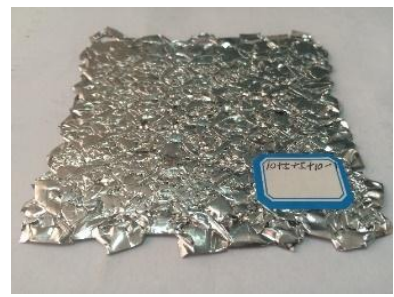

(d) $\mathrm{B}+\mathrm{A}+\mathrm{A}+\mathrm{B}$

Fig. (12). Crushed four layered aluminum honeycombs.

\subsection{Discussion}

By comparing the single layer honeycombs, it can be found that the peak force is almost $2 \sim 3$ times than the mean plateau force; the two value of $A$ specimen were higher than that of $B \sim B 2$; the absorbing energy level of $A$ is almost 3 times of the latter's; Due to the increase of the height, the aluminum foil lining can easily lead to buckling; since the A has smaller MP ratio than $\mathrm{B}$, it is considered to be beneficial to energy absorption.

For double layered aluminum honeycomb, the structure with equal height layers would enter into the yield stage after mutual inserting, it was equivalent to make the peak force into superposition. On the other hand, the honeycomb structure with unequal height layers would yield into two stages, the peak force had been separated into two parts. Therefore, the honeycomb with unequal height layers has better buffer performance which can be inferred from the MP ratio. In the three groups of experiments, with more A layer take a part in compression, the higher the mean inserting force, peak force, mean plateau force and energy absorption are. However, the disadvantage of the high stiffness is that with higher peak force, it has a negative effect on the buffer performance.

The experimental results of triple layered aluminum honeycomb showed that: the curves of honeycombs with three layers are more smooth; the absorbing energy level of $\mathrm{A}+\mathrm{A}+\mathrm{A}$ combination is the highest among the triple layered aluminum honeycombs. However, the energy absorption performance of this combination is not ideal. The $\mathrm{A}+\mathrm{B}+\mathrm{A}$ combination has better ability in energy absorption than the $\mathrm{A}+\mathrm{A}+\mathrm{B}$ combination, which is relevant with the crush behavior. By comparing the $\mathrm{B}, \mathrm{B}+\mathrm{B}$ and the $\mathrm{B}+\mathrm{B}+\mathrm{B}$ combination, it showed that with the increase of layers, the $\mathrm{MP}$ ratio will decrease.

The experimental results of four layered aluminum honeycomb showed that: the force-displacement curve of the honeycomb with four layers becomes more smooth; Nevertheless, the main energy absorption stage can hardly play a part.

According to the section 3.3 and 3.4, it can be concluded that the combination of placing soft layer between hard layers is better than the others.

\section{CONCLUSION}

The experiments of layered aluminum honeycomb structures under quasi-static load had been carried out, mainly includes single, double, triple, four layer combinations. The results showed that: the peak force and the mean plateau force of single-layer aluminum honeycomb structure are proportional to the surface density, however they decline slightly with increase of the height; unequal height double layered aluminum honeycomb structure has more advantage in cushion performance; with the increase of layers, the MP ratio will decrease; the combination of placing soft layer between hard layers is better than the others.

\section{CONFLICT OF INTEREST}

The authors confirm that this article content has no conflict of interest.

\section{ACKNOWLEDGEMENTS}

This work was supported by grant from National Natural Science Foundation of China (NO. 51378495, NO. 51408602), Chongqing Natural Science Foundation (cstc2012jjA30005, cstc2012jjB30004) and Bureau of Land Resources and Housing Management of Chongqing. 


\section{REFERENCES}

[1] M.K. Khan, T. Baig, and S. Mirza, "Experimental investigation of in-plane and out-of-plane crushing of aluminum honeycomb", Materials Science and Engineering $A$, vol. 539, pp. 135-142, 2012.

[http://dx.doi.org/10.1016/j.msea.2012.01.070]

[2] A. Wilbert, W.Y. Jang, S. Kyriakides, and J.F. Floccari, "Buckling and progressive crushing of laterally loaded honeycomb", International Journal of Solids and Structures, vol. 48, pp. 803-816, 2011. [http://dx.doi.org/10.1016/j.ijsolstr.2010.11.014]

[3] C. Wang, R.Q. Liu, and Z.Q. Deng, "Experimental and numerical studies on aluminum honeycomb structure with various cell specifications under impact loading", Journal of Vibration and Shock, vol. 27, pp. 121-126, 2008.

[4] S. Xu, J.H. Beynon, R. Dong, and G. Lu, "Experimental study of the out-of-plane dynamic compression of hexagonal honeycombs", Composite Structures, vol. 94, pp. 2326-2336, 2012. [http://dx.doi.org/10.1016/j.compstruct.2012.02.024]

[5] S. Xu, R. Dong, and J.H. Beynon, "Finite element analysis of the dynamic behavior of aluminum honeycombs", International Journal of Computational Methods, vol. 11, pp. 1-16, 2014.

[http://dx.doi.org/10.1142/S0219876213440015]

[6] D.Q. Sun, W.H. Zhang, and Y.B. Wei, "Mean out-of-plane dynamic plateau stresses of hexagonal honeycomb cores under impact loadings", Composite Structures, vol. 92, pp. 2609-2621, 2010. [http://dx.doi.org/10.1016/j.compstruct.2010.03.016]

[7] A. Niknejad, and D.M. Rahmani, "Experimental and theoretical study of the lateral compression process on the empty and foam-filled hexagonal columns", Materials \& Design, vol. 53, pp. 250-261, 2014. [http://dx.doi.org/10.1016/j.matdes.2013.06.077]

[8] W.H. Lu, and R.H. Bao, "Mechanical analysis of the impacted honeycombs", Journal of Vibration and Shock, vol. 24, pp. 49-52, 2005.

[9] E. Wu, and W.S. Jiang, "Axial crush of metallic honeycombs", International Journal of Impact Engineering, vol. 19, pp. 439-456, 1997. [http://dx.doi.org/10.1016/S0734-743X(97)00004-3]

[10] M. Yamashita, and M. Gotoh, "Impact behavior of honeycomb structures with various cell specifications-numerical simulation and experiment", International Journal of Impact Engineering, vol. 32, pp. 618-630, 2005. [http://dx.doi.org/10.1016/j.ijimpeng.2004.09.001]

[11] S.B. Tan, B. Hou, Y.L. Li, H. Zhao, and S.O. Aeronautics, "Effect of base materials on the dynamic enhancement of aluminum honeycombs", Explosion and Shock Waves, vol. 35, pp. 16-21, 2015. [http://dx.doi.org/10.11883/1001-1455(2015)01-0016-06]

[12] A. Ashab, R. Dong, G. Lu, S. Xu, and C. Wen, "Experimental investigation of the mechanical behavior of aluminum honeycombs under quasi-static and dynamic indentation", Materials and Design, vol. 74, pp. 138-149, 2015. [http://dx.doi.org/10.1016/j.matdes.2015.03.004]

[13] Y.L. Lin, Z.F. Zhang, R. Chen, Y. Li, X.J. Wen, and F.Y. Lu, "Cushioning and energy absorbing property of combined aluminum honeycomb", Advanced Engineering Materials, vol. 17, pp. 1434-1441, 2015. [http://dx.doi.org/10.1002/adem.201400574]

[14] L. Cao, Y.L. Lin, F.Y. Lu, R. Chen, Z.F. Zhang, and Y. Li, "Experimental study on the shock absorption performance of combined aluminium honeycombs under impact loading", Shock and Vibration, vol. 1, pp. 1-8, 2015. [http://dx.doi.org/10.1155/2015/689546]

(C) Luo et al.; Licensee Bentham Open

This is an open access article licensed under the terms of the Creative Commons Attribution-Non-Commercial 4.0 International Public License (CC BY-NC 4.0) (https://creativecommons.org/licenses/by-nc/4.0/legalcode), which permits unrestricted, non-commercial use, distribution and reproduction in any medium, provided the work is properly cited. 